\title{
A Community-Based Survey to Assess Knowledge, Attitudes, Beliefs and Practices Regarding Herpes Zoster in an Urban Setting
}

\author{
Nour A. Baalbaki · Joseph P. Fava (D) - Melanie Ng · Ezinwanne Okorafor • \\ Asad Nawaz · Wesley Chiu · Abdulbaset Salim • Raymond Cha • \\ Paul E. Kilgore
}

Received: August 8, 2019 / Published online: October 3, 2019

(C) The Author(s) 2019

\section{ABSTRACT}

Introduction: In the USA, nearly one in three people will experience herpes zoster (HZ) in their lifetime. Underserved communities may be at even higher risk due to several factors, including access to healthcare, education, and co-morbid conditions. The purpose of this study was to investigate current knowledge, attitudes,

Enhanced Digital Features To view enhanced digital features for this article go to https://doi.org/10.6084/ m9.figshare.9901172.

Electronic supplementary material The online version of this article (https://doi.org/10.1007/s40121019-00269-2) contains supplementary material, which is available to authorized users.

N. A. Baalbaki · J. P. Fava $(\bowtie) \cdot$ M. Ng $\cdot$ W. Chiu . A. Salim - P. E. Kilgore Department of Pharmacy Practice, Wayne State University Eugene Applebaum College of Pharmacy and Health Sciences, Detroit, MI, USA

e-mail: joseph.fava@wayne.edu

E. Okorafor

Department of Basic Medical Science, Wayne State University, Detroit, MI, USA

\section{A. Nawaz}

Department of Economics, Wayne State University, Detroit, MI, USA

R. Cha

Department of Pharmacy Practice, School of Pharmacy and Pharmaceutical Sciences, University at Buffalo, Buffalo, NY, USA beliefs and practices (KABP) relative to $\mathrm{HZ}$ and $\mathrm{HZ}$ vaccines in a large urban city.

Methods: A cross-sectional KABP survey was conducted via in-person interview among 381 participants aged $\geq 50$ years in Detroit, MI, USA, from June to August 2018. Survey results were stratified into two groups $[<60$ and $\geq 60$ years of age $(\mathrm{YO})]$ for comparison.

Results: Of the 381 participants, 373 reported their age $(110<60 \mathrm{YO}$ and $263 \geq 60 \mathrm{YO})$. Overall, the majority of participants reported having heard of $\mathrm{HZ}$ and $\mathrm{HZ}$ vaccines. In addition, receiving a recommendation from a healthcare provider $(37.5 \%)$ followed by gaining a better understanding of $\mathrm{HZ}$ vaccine (36.7\%) and of HZ (29.9\%) were leading factors that influenced participants' willingness to receive the vaccine. Of note, $65.5 \%$ of participants $<60$ YO reported the belief that $\mathrm{HZ}$ is preventable versus only $53.2 \%$ in those $\geq 60$ YO $(p=0.001)$.

Conclusion: Our findings underscore the need to educate patients in underserved communities about $\mathrm{HZ}$ as well as new $\mathrm{HZ}$ vaccine recommendations to improve vaccination rates and reduce the incidence of $\mathrm{HZ}$ and its associated sequelae.

Keywords: Herpes zoster; Shingles; Survey; Vaccination 


\section{INTRODUCTION}

Herpes zoster (HZ), or shingles, results from reactivation of the varicella-zoster virus. It is estimated that one out of every three people in the USA will develop HZ during their lifetime, and $13 \%$ of people $\geq 60$ years of age will develop post-herpetic neuralgia (PHN), which can significantly reduce quality of life [1]. Despite the recognized burden of $\mathrm{HZ}$ and $\mathrm{PHN}$, HZ vaccination rates in the US remain low. Whites have significantly higher $\mathrm{HZ}$ vaccination rates (37.7\%) compared with Asians (21.9\%), Hispanics (21.4\%) and African Americans (15.7\%) [2]. Additional factors such as education, household income and existing relationship with a healthcare provider have been independently associated with $\mathrm{HZ}$ vaccination [3]. Such disparities in HZ immunization rates may reflect the interrelationship of health and socioeconomic disparities between these racial/ethnic groups found across the US [4].

In October 2017, the US Food and Drug Administration approved a new recombinant zoster vaccine, Shingrix ${ }^{\circledR}$ (GlaxoSmithKline, Rixensart, Belgium). Evidence shows the efficacy of Shingrix ${ }^{\circledR}$ against HZ at $97 \%$, a substantial improvement from $51 \%$ displayed by the live zoster vaccine, Zostavax ${ }^{\circledR}$ (Merck \& Co., Inc., Whitehouse Station, NJ, USA), the only HZ vaccine available in the US prior the approval of Shingrix ${ }^{\circledR}[5,6]$. Increasing patient uptake of this new and more effective vaccine has potential to significantly reduce $\mathrm{HZ}$ disease burden. Thus, it is important to gauge patient understanding of $\mathrm{HZ}$ and $\mathrm{HZ}$ vaccines, particularly in disadvantaged populations that suffer from health disparities. In this report, we assess knowledge, attitudes, beliefs and practices (KABP) among people residing in a large urban American city with a high proportion of medically underserved individuals and families to identify potential opportunities to improve HZ awareness and vaccine uptake.

\section{METHODS}

\section{Study Overview}

A KABP survey was developed, and convenience sampling was conducted at four different locations (two large retail stores located in the city's suburban neighborhoods and two community centers located in combined commercial/residential districts) in Detroit, MI, USA. This city was chosen because it houses the institution conducting the study and is demographically characteristic of an underserved area with significant healthcare disparities. According to the US Health Resources \& Services Administration, Detroit is a federally designated health professional shortage area for primary care, and nearly every square mile of the city is designated as a medically underserved area [7]. The city's population is just over 670,000 residents, $79.1 \%$ of whom are Black or African American, 9.9\% White and 7.6\% Hispanic or Latinx [8]. In addition, the median household income in Detroit in 2017 was $\$ 27,838$, and $37.9 \%$ of its residents live in poverty [8].

Participants were recruited via flyers and/or approached in person by study personnel, and verbal agreement to participate in the survey was obtained. All participants received a study information sheet. Upon verbal consent and confirmation that their age was $\geq 50$ years by study personnel (participants asked: "are you 50 years or older?" and this question was included in the demographic section of the survey), study personnel then performed a faceto-face interview using a paper-based survey instrument. After completing the survey, participants received HZ-based educational handouts and a $\$ 10.00$ gift card to a local retailer. People who had never heard of shingles were excluded from this study. The Wayne State University Institutional Review Board reviewed and approved this study (reference no. 043918B3X). This study conformed with the Helsinki Declaration of 1964, as revised in 2013, concerning human and animal rights, and Springer's policy concerning informed consent has been followed. 


\section{Survey Instrument}

The survey is available in the supplementary material and consisted of 42 multiple-choice items. It consisted of five sections: demographic, knowledge (20 items), attitudes (11 items), beliefs and influence of practice toward $\mathrm{HZ}$ vaccines (11 items). HZ was referred to as 'shingles' in the survey. Participants were instructed to completely answer each item based on their current knowledge.

\section{Data Collection and Statistical Analysis}

Sample size estimation assumed a statistical power of 0.8 and a confidence level of $95 \%$ (alpha $=0.05)$. Assuming a target population of 209,409 aged $\geq 50$ years in Detroit, and an overall response rate of at least $80 \%$, we estimated a required sample size of 350 individuals. Surveys were administered by trained key personnel from June to August 2018. Answers from paper-based surveys were transcribed into the Research Electronic Data Capture (REDCap) tool (est. 2004 Vanderbilt University, Nashville, TN) and analyzed using SPSS (ver. 24) statistical analysis software (2016; IBM Corp. Armonk, NY). Univariate (chi-square or Fisher's exact test) analyses were used to describe patterns of KABPs among participants. A $p$ value $<0.05$ was considered significant.

\section{RESULTS}

\section{Participant Demographics}

Three hundred eighty-one participants completed the survey, and of these 373 provided information on age. Sixty-five percent $(n=241)$ of participants were female, and $90.3 \%$ $(n=344)$ were Black or African American. Participants were stratified into two groups [age $<$ 60 or $\geq 60$ years old (YO); Fig. 1]. This age cutoff was chosen to allow for better understanding of zoster knowledge, behaviors and practices among those at lower or greater risk for $\mathrm{HZ}$ [1].

\section{Knowledge of $\mathrm{HZ}$ and $\mathrm{HZ}$ Vaccines}

When asked "do you think that shingles is common in the US," the majority of both groups $(<60$ YO and $\geq 60$ YO) chose "yes" $(69.1 \%$ and $68.5 \%)$. The majority also reported knowing at least one person who had $\mathrm{HZ}$ in the past $(68.2 \%$ and $68.4 \%) ; 13.3 \%$ of participants $\geq 60$ YO had reported experiencing HZ personally compared with only $8.2 \%$ of participants $<60$ YO. The majority of both groups knew that HZ is a nerve/skin disease $(96.4 \%$ and $93.1 \%)$, and that adults aged $\geq 50$ years had a higher risk of HZ (69.1\% and $66.9 \%)$ than those $<50$ years. Participants of both age groups selected post-herpetic neuralgia (PHN) as the most common complication of $\mathrm{HZ}(40.4 \%$ and $44.4 \%)$ followed by rash $(39.7 \%$ and $33.2 \%)$. Participants of both age groups knew that HZ can be recurrent $(61.8 \%$ and $58.6 \%)$ and that $\mathrm{HZ}$ is not transmitted person to person $(49.1 \%$ and $56.3 \%)$.

Most participants of both groups $(<60 \mathrm{YO}$ and $\geq 60 \mathrm{YO}$ ) had heard of the $\mathrm{HZ}$ vaccine (Fig. 2). The most common information source for hearing about the $\mathrm{HZ}$ vaccine was television or internet advertisements $(36.0 \%$ and $37.2 \%)$ followed by their doctor (25.2\% and $31.4 \%)$ and their pharmacist $(9.7 \%$ and $14.2 \%)$. Interestingly, a significantly higher proportion of respondents $<60 \mathrm{YO}(62.7 \%)$ felt that the $\mathrm{HZ}$ vaccine was associated with side effects versus those $\geq 60$ YO (39.2\%; $p<0.001)$, and 35\% $(29.1 \%$ in $<60$ YO and $36.9 \%$ in $\geq 60 \mathrm{YO})$ of overall participants did not know that the HZ vaccine was associated with any side effects.

\section{Attitudes and Beliefs Toward HZ and HZ Vaccines}

Most participants of both groups believed that HZ can be treated (92.7\% and 93.9\%). Of those, $67.6 \%$ of participants $<60$ YO thought treatments were safe and effective compared with $71.3 \%$ of participants $\geq 60$ YO. Over half of participants of both groups thought HZ is curable $(60.0 \%$ and $63.1 \%)$. However, only $53.2 \%$ of participants $\geq 60 \mathrm{YO}$ thought $\mathrm{HZ}$ is preventable compared with $65.5 \%$ of 


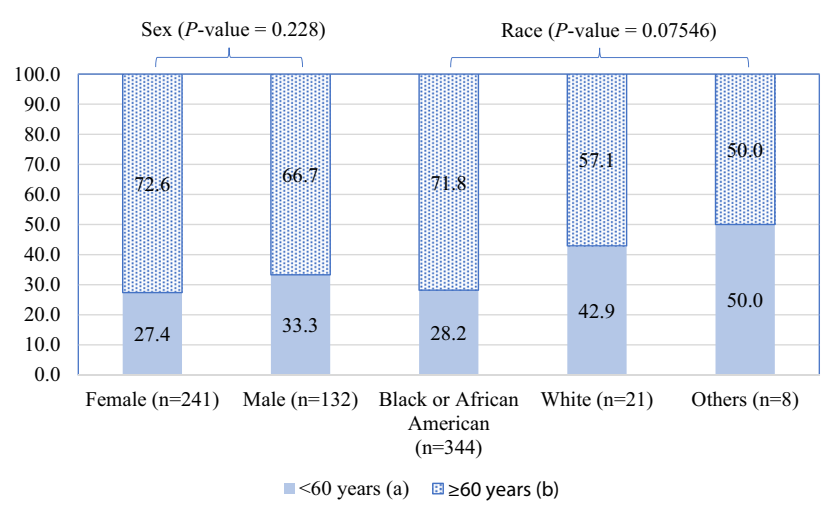

Fig. 1 Demographic characteristics of participants (\%) by age group. ${ }^{a}$ Mean (standard deviation): 54.4 (3.1) years. Range 50-59 years. ${ }^{b}$ Mean (standard deviation): 68.3 (6.6) years. Range 60-92 years

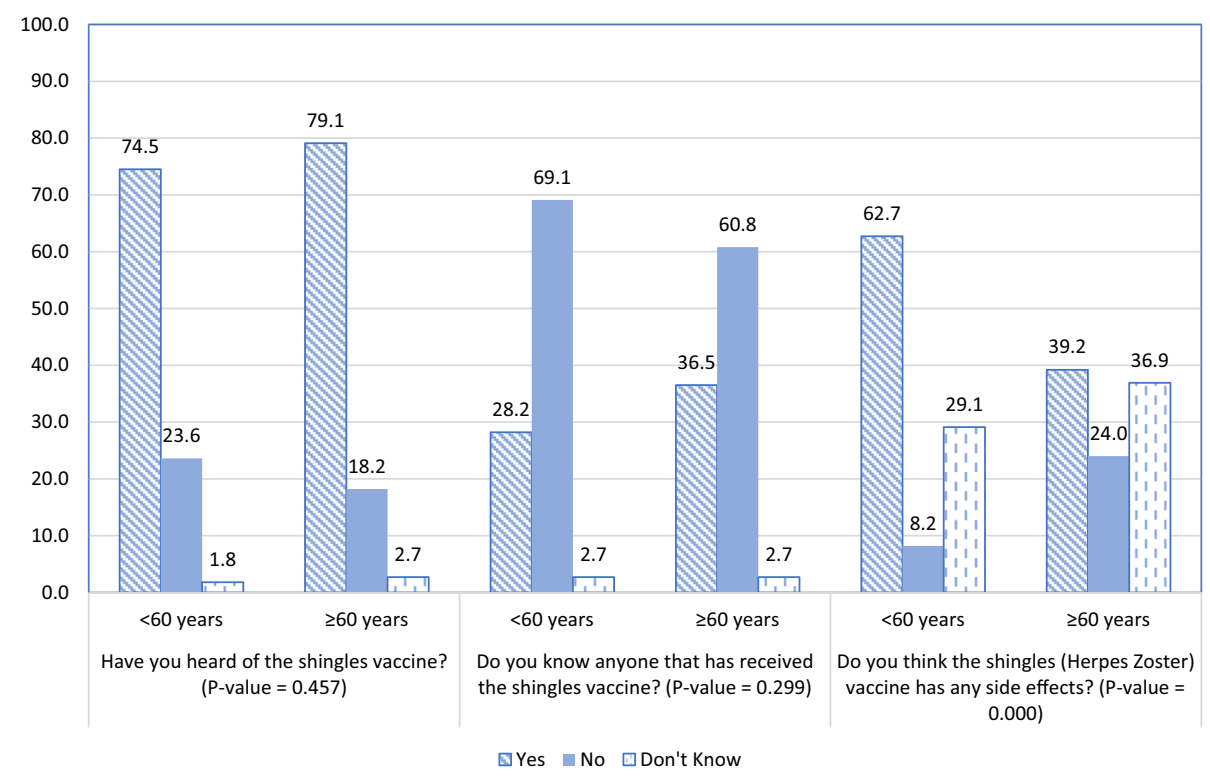

Fig. 2 Knowledge of herpes zoster vaccines

participants $<60$ YO $(p=0.001)$. About $18 \%$ of both groups thought that it was very unlikely that they could experience shingles while only $12 \%$ thought they were very likely to get shingles, now or in the future. Most participants thought that the pain associated with $\mathrm{HZ}$ is serious $(67.3 \%$ and $60.5 \%)$.

In questions related to vaccine safety and efficacy, $>50 \%$ of participants of both groups believed that $\mathrm{HZ}$ vaccines were safe and effective. Additional survey data related to attitudes and beliefs are shown in Fig. 3 .

\section{Practices Toward HZ and HZ Vaccines}

Only $19.1 \%$ of participants $<60$ YO indicated that they received a recommendation for a shingles vaccine from their healthcare provider versus $43.3 \%$ of participants $\geq 60 \quad \mathrm{YO}$ $(p=0.000)$ (Table 1). Willingness to receive the shingles vaccine was reported among $46.4 \%$ of participants $<60$ YO compared with $50.2 \%$ in participants $\geq 60 \mathrm{YO}(p=0.750)$. In addition, a high proportion of participants in both the younger and older age groups expressed a willingness to seek more information from a 


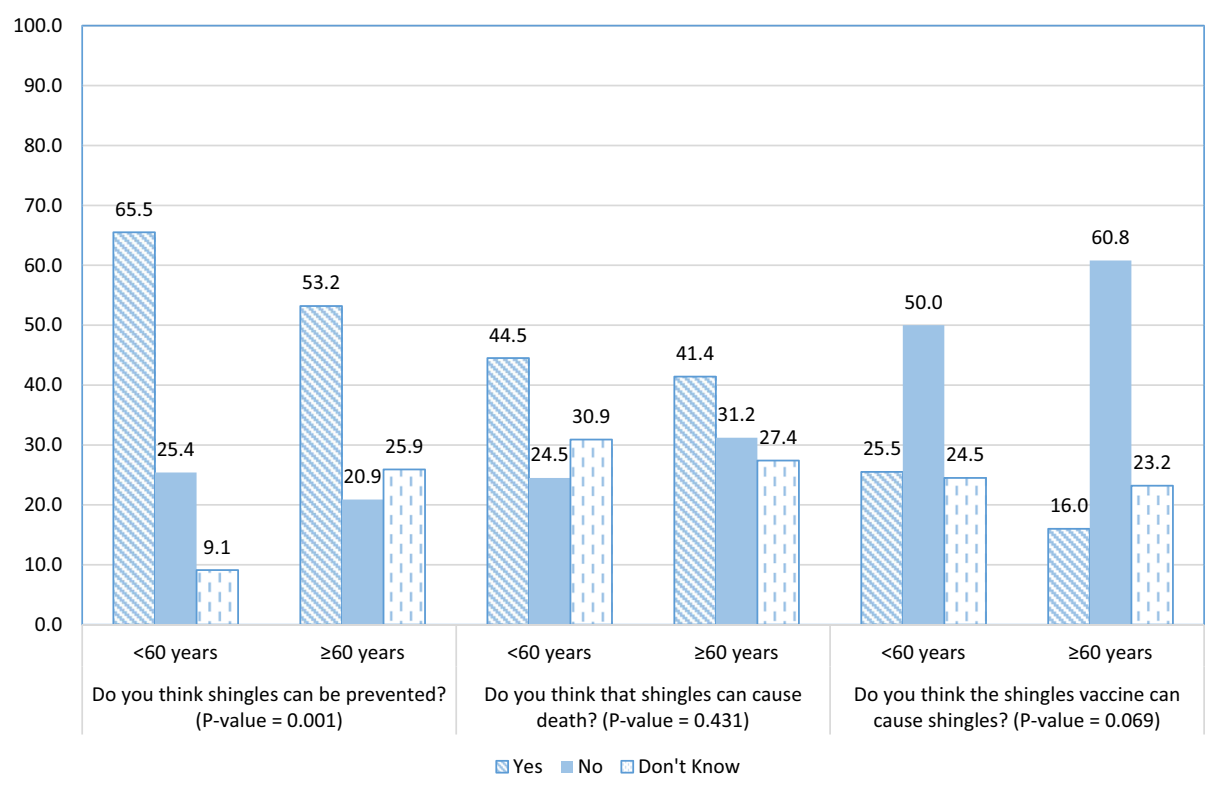

Fig. 3 Attitudes and beliefs regarding shingles and shingles vaccines

Table 1 Practices toward herpes zoster and herpes zoster vaccines

\begin{tabular}{|c|c|c|c|c|}
\hline Characteristic & $N$ & Age (y & & $P$ value \\
\hline & & $\begin{array}{l}<60 \\
n(\%)\end{array}$ & $\begin{array}{l}\geq 60 \\
n(\%)\end{array}$ & \\
\hline
\end{tabular}

Did your doctor/pharmacist or other healthcare provider ever recommend you to be vaccinated with the shingles vaccine?

\begin{tabular}{|c|c|c|c|}
\hline Yes & 135 & $21(19.1)$ & $114(43.3)$ \\
\hline No & 238 & 89 (80.9) & $149(56.7)$ \\
\hline
\end{tabular}

All other things being equal, if you are offered a shingles vaccine that is $97.2 \%$ protective and requires two doses gives 2 months apart (vaccine \#1) or a shingles vaccine that is $51.3 \%$ protective and requires one dose (vaccine \#2), which vaccine would you choose?

Vaccine \#1

Vaccine \#2

$52 \quad 10(9.1) \quad 42(16.0)$

Others

$8 \quad 3(2.7) \quad 5(1.9)$

healthcare provider about the shingles vaccine (84.5\% in $<60 \mathrm{YO}$ vs. $87.1 \%$ in $\geq 60 \mathrm{YO})$.

We asked both age groups whether they would be willing to receive the vaccine based on a recommendation from three different healthcare professionals: a doctor, a nurse and a pharmacist; $71.8 \%$ of participants $<60 \mathrm{YO}$ and $73.0 \%$ of those $\geq 60$ YO stated they would based on a doctor's recommendation followed by recommendation from a nurse $(53.6 \%$ and $54.0 \%)$ and, lastly, a recommendation from a pharmacist (48.2\% and $45.6 \%)$, respectively. No 
significant differences were found in willingness to take healthcare provider recommendations when comparing the two age groups.

When given the choice between "vaccine \#1 (97.2\% protective, requiring two doses 2 months apart) vs. vaccine \#2 (51.3\% protective, requiring one dose)," $88.2 \%$ of respondents $<60$ YO selected vaccine \#1 compared with $82.1 \%$ of respondents $\geq 60 \mathrm{YO}(p=0.200)$.

Regarding vaccine cost, $31.4 \%$ of participants reported willingness to receive the vaccine only if it were provided free of charge. Thirty-six percent of participants were willing to pay up to $\$ 24.99$ USD, and $18.7 \%$ were willing to pay $\$ 25.00$ to 50.00 USD. One-hundred forty-three $(37.5 \%)$ participants reported that a recommendation by a healthcare provider was the most important factor that would change their decision to receive the vaccine followed by gaining a better understanding of the vaccine $(36.7 \%)$, gaining a better understanding of the disease $(29.9 \%)$, reduced cost of the vaccine (11.8\%) and "other" factor(s) (3.7\%).

\section{DISCUSSION}

In a representative sample of medically underserved and socioeconomically challenged participants, knowledge, attitudes, beliefs and practices regarding $\mathrm{HZ}$ and $\mathrm{HZ}$ vaccines were highly variable. These findings are consistent with existing studies, including those in characteristically different populations [9-11].

Our results demonstrate that provider recommendations play a vital role in promoting $\mathrm{HZ}$ vaccination by positively influencing willingness to receive the vaccine. This concept has been displayed in a similar study by Teeter et al., which found that among 681 participants, there was over a fivefold increase in likelihood of vaccination if they received a recommendation from a healthcare provider [12]. It should be noted however that the majority of participants in this study were white and unvaccinated. Our study provides a unique perspective, as it is the only survey on $\mathrm{HZ}$ and $\mathrm{HZ}$ vaccines, to our knowledge, that was conducted in an underserved, urban environment with a socioeconomically challenged population.
Despite the importance of provider recommendations, only $36.1 \%$ of survey respondents reported receiving a recommendation for the shingles vaccine from their healthcare provider, representing a significant missed opportunity to more frequently and effectively educate eligible patients [13]. Furthermore, despite a lower recommendation acceptance rate compared with doctors and nurses, pharmacists' ability to provide vaccinations and their increased accessibility compared with other healthcare providers represent another opportunity for patient education. Efforts that provide training to pharmacists in vaccine communication with patients and caregivers may help reduce missed vaccination opportunities at the pharmacy level.

In the US and other countries, the high cost of the $\mathrm{HZ}$ vaccine is a well-established barrier to vaccination [14]. However, results of our study revealed that reducing the cost of the $\mathrm{HZ}$ vaccine was only the fourth most important factor that would change participants' decision to receive the vaccine, when given the choice of the following factors: recommendation by a healthcare provider, gaining a better understanding of the $\mathrm{HZ}$ vaccine, gaining a better understanding of $\mathrm{HZ}$, reduced cost of the vaccine and 'other.' These data suggest that vaccine cost is not the sole reason for the inability to receive $\mathrm{HZ}$ vaccination among patients in medically underserved communities. Other reasons for not receiving $\mathrm{HZ}$ vaccination include important factors such as having adequate insurance coverage and access to transportation.

The efficacy of existing vaccines against $\mathrm{HZ}$ and the number of doses required were found to be other important factors in willingness to receive vaccinations. Given efficacy rates and dose series requirements of the two $\mathrm{HZ}$ vaccines currently utilized, the vast majority of participants stated they would choose the option with a higher efficacy rate, even if it required two doses instead of just one. This shows that providing patients basic evidentiary information on vaccines can be a major tool to overcome the barrier of multiple-dose requirements, even in the medically underserved. 
A few limitations apply to our study. First, our survey was investigator-created and nonvalidated. Survey responses were self-reported and are thus susceptible to recall bias. In addition, although the survey was conducted in a medically underserved demographic, we were unable to verify the educational background and/or socioeconomic status of each participant, as this information was not collected. Lastly, because this survey was conducted in a primarily African American population, the results may be less representative of other populations with a predominance of other racial/ ethnic groups.

\section{CONCLUSION}

Our findings contribute to understanding the KABPs regarding $\mathrm{HZ}$ and $\mathrm{HZ}$ vaccines in a sample of primarily African American persons in a medically underserved, socioeconomically challenged community. Our study suggests that lack of vaccine recommendations from healthcare providers may be a significant factor influencing low $\mathrm{HZ}$ vaccination rates in these communities. It is crucial to educate patients about $\mathrm{HZ}$ and its complications, as well as basic information regarding $\mathrm{HZ}$ vaccines, to improve vaccination rates and reduce the incidence of HZ. Future research should focus on continued identification of barriers to vaccination through KABP assessment in diverse populations and training all types of HCPs to improve the delivery and increase the frequency of recommendations for $\mathrm{HZ}$ vaccination to their patients.

\section{ACKNOWLEDGEMENTS}

The authors would like to thank key personnel Adalah Yahia, Katherine Chuong, Mariam Hijazi, Mary Whitney, Maryam Al-Jazrawi, Mohamad Akil, Nesreen Altairy, Rana Aoun and Riham Mansour for their assistance with survey administration. The authors would also like to thank all survey respondents for participating in this study.
Funding. This work was supported by the Wayne State University Department of Pharmacy Practice Research \& Development fund. No Rapid Service Fee was received by the journal for the publication of this article.

Authorship. All named authors meet the International Committee of Medical Journal Editors (ICMJE) criteria for authorship for this article, take responsibility for the integrity of the work as a whole, and have given their approval for this version to be published.

Disclosures. Nour A. Baalbaki, Joseph P. Fava, Melanie Ng, Ezinwanne Okorafor, Asad Nawaz, Wesley Chiu, Abdulbaset Salim, Raymond Cha and Paul E. Kilgore have nothing to disclose. Paul E. Kilgore is an Editorial Board Member for the journal.

Compliance with Ethics Guidelines. The Wayne State University Institutional Review Board reviewed and approved this study (reference number: 043918B3X). This study conformed with the Helsinki Declaration of 1964, as revised in 2013, concerning human and animal rights, and Springer's policy concerning informed consent has been followed.

Data Availability. The datasets generated during and/or analyzed during the current study are available in the Mendeley repository [http://dx.doi.org/10.17632/sykkm7rx4m.1].

Open Access. This article is distributed under the terms of the Creative Commons Attribution-NonCommercial 4.0 International License (http://creativecommons.org/licenses/ by-nc/4.0/), which permits any noncommercial use, distribution, and reproduction in any medium, provided you give appropriate credit to the original author(s) and the source, provide a link to the Creative Commons license, and indicate if changes were made.

\section{REFERENCES}

1. Harpaz R, Ortega-Sanchez IR, Seward JF. Prevention of herpes zoster: recommendations of the Advisory 
Committee on Immunization Practices (ACIP). Morb Mortal Weekly Rep. 2008;57:1-30 (quiz CE2-4. Epub 2008/06/06 PubMed PMID: 18528318).

2. Saguil A, Kane S, Mercado M, et al. Herpes zoster and postherpetic neuralgia: prevention and management. Am Fam Physician. 2017;96(10):656-63 (Epub 2018/02/13 PubMed PMID: 29431387).

3. Lu PJ, O'Halloran A, Williams WW, et al. National and state-specific shingles vaccination among adults aged $>/=60$ years. Am J Prev Med. 2017;52(3):362-72. https://doi.org/10.1016/j. amepre.2016.08.031 (Epub 2016/10/11. PubMed PMID: 27720342; PubMed Central PMCID: PMCPMC5818280).

4. Williams DR, Mohammed SA. Discrimination and racial disparities in health: evidence and needed research. J Behav Med. 2009;32(1):20-47. https:// doi.org/10.1007/s10865-008-9185-0 (Epub 2008/11/26. PubMed PMID: 19030981; PubMed Central PMCID: PMCPMC2821669).

5. Shingrix (Zoster Vaccine Recombinant, Adjuvanted). GlaxoSmithKline Biologicals, Rixensart, Belgium; 2017. https://gsksource.com/pharma/ content/dam/GlaxoSmithKline/US/en/Prescribing Information/Shingrix/pdf/SHINGRIX.PDF. Accessed 27 Sept 2019.

6. Oxman MN, Levin MJ, Johnson GR, et al. A vaccine to prevent herpes zoster and postherpetic neuralgia in older adults. $\mathrm{N}$ Engl J Med. 2005;352(22):2271-84. https://doi.org/10.1056/ nejmoa051016 (Epub 2005/06/03. PubMed PMID: 15930418).

7. Map Tool: data.HRSA.gov. https://data.hrsa.gov/ hdw/tools/MapTool.aspx. Accessed 19 Sept 2019.
8. QuickFacts: Detroit city, Michigan. United States Census Bureau. https://www.census.gov/quickfacts/ detroitcitymichigan. Accessed 6 Dec 2018.

9. Paek E, Johnson R. Public awareness and knowledge of herpes zoster: results of a global survey. Gerontology. 2010;56(1):20-31. https://doi.org/10.1159/ 000240046 (Epub 2009/09/25. PubMed PMID: 19776543).

10. Valente N, Lupi S, Stefanati A, et al. Evaluation of the acceptability of a vaccine against herpes zoster in the over 50 years old: an Italian observational study. BMJ open. 2016;6(10):e011539. https://doi. org/10.1136/bmjopen-2016-011539 (Epub 2016/11/01. PubMed PMID: 27797989; PubMed Central PMCID: PMCPMC5073480).

11. Joon Lee T, Hayes S, Cummings DM, et al. Herpes zoster knowledge, prevalence, and vaccination rate by race. J Am Board Fam Med. 2013;26(1):45-51. https://doi.org/10.3122/jabfm.2013.01.120154 (Epub 2013/01/05. PubMed PMID: 23288280).

12. Teeter BS, Garza KB, Stevenson TL, et al. Factors associated with herpes zoster vaccination status and acceptance of vaccine recommendation in community pharmacies. Vaccine. 2014;32(43):5749-54. https://doi.org/10.1016/j.vaccine.2014.08.040 (Epub 2014/08/31. PubMed PMID: 25171848).

13. Nowalk MP, Zimmerman RK, Cleary SM, et al. Missed opportunities to vaccinate older adults in primary care. J Am Board Fam Pract. 2005;18(1):20-7 (Epub 2005/02/15 PubMed PMID: 15709060).

14. Hurley LP, Lindley MC, Harpaz R, et al. Barriers to the use of herpes zoster vaccine. Ann Intern Med. 2010;152(9):555-60. https://doi.org/10.7326/00034819-152-9-201005040-00005 (Epub 2010/05/05. PubMed PMID: 20439573). 